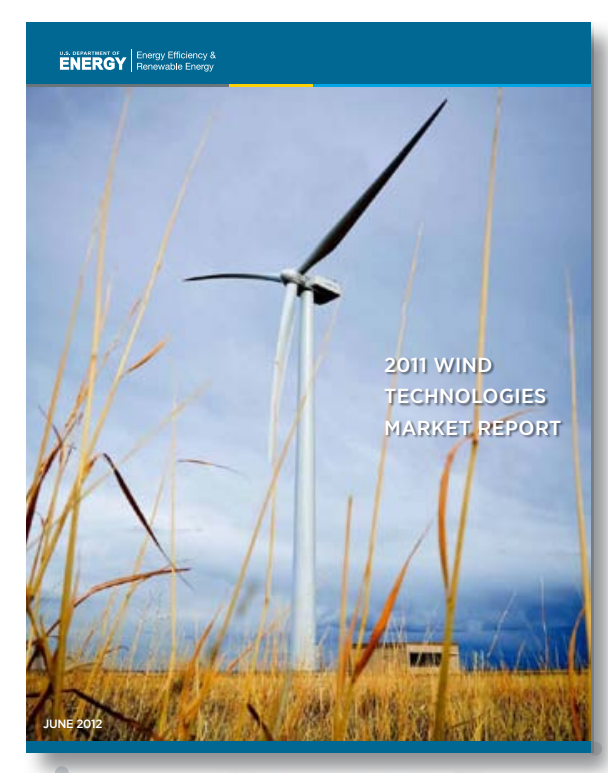

\title{
Coming Soon!
}

\section{Wind Technologies Market Report}

This valuable report will be available this summer! Prepared by the Energy Department's Lawrence Berkeley National Laboratory, the report is a must read, providing a comprehensive overview of United States wind industry:

- Installation Trends

- Industry Trends

- Price, Cost, and Performance Trends

- Policy and Market Drivers

- Future Outlook

Download your copy at wind.energy.gov, or sign up for Wind Program Breaking News to receive it by email.

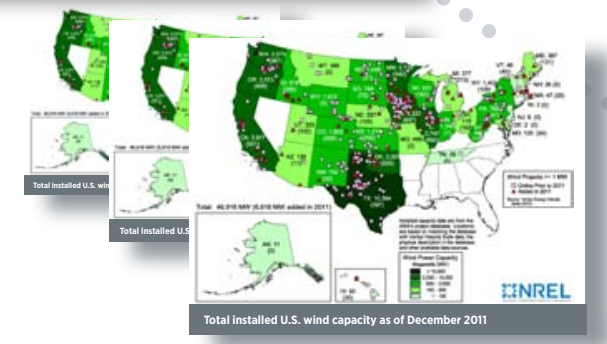


The United States Department of Energy Wind Program partners with national laboratories, industry, universities, and other federal agencies to conduct research and development efforts to deploy clean wind power technologies across the nation.

\section{Stay connected ... Subscribe at wind.energy.gov}

Interested in Wind Program Breaking News? The Wind Program offers timely e-mail updates for funding opportunities, events, publications and program activities.

Sign up for the Wind Program Quarterly Newsletter to receive recent news about the program's R\&D projects, accomplishments, upcoming events, funding opportunities, and recent publications.

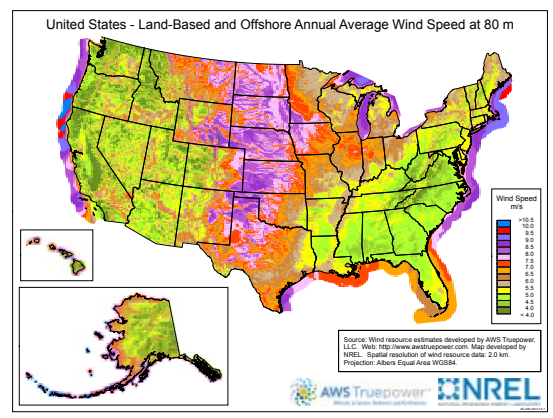

\section{New}

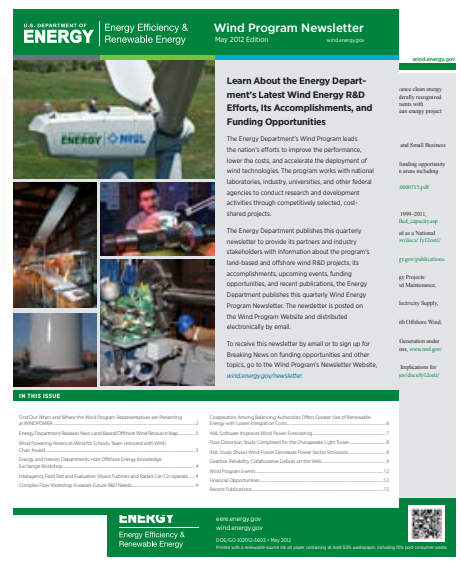

Wind resource map shows land-based and offshore wind resource potential. Join the 20,000 developers, policy makers, and website users who look at these wind maps each month to identify areas of significant resource for wind farm planning. Download your copy today!

Visit wind.energy.gov for up-to-date wind power news today! 